ARTICLE

Received 27 Nov 2015 | Accepted 31 Mar 2016 | Published 10 May 2016

DOI: $10.1057 /$ palcomms.2016.16

\title{
Ensuring science is useful, usable and used in global disaster risk reduction and sustainable development: a view through the Sendai framework lens
}

\author{
Amina Aitsi-Selmi ${ }^{1}$, Kevin Blanchard ${ }^{1}$ and Virginia Murray ${ }^{1,2}$
}

\begin{abstract}
The recently adopted United Nations' Sendai Framework on Disaster Risk Reduction 2015-2030 has a much greater emphasis on science compared with other global policy frameworks. It builds on the idea that science and evidence are essential for effective policy-making to improve lives, livelihoods and health. It was the first UN landmark agreement of the year 2015, the other two being the Sustainable Development Goals (agreed September 2015) and the Climate Change Agreements (agreed December 2015). This article explores key synergies across these agreements that are articulated in the Sendai Framework to support joint policy-making. The article outlines the opportunities and challenges for scientific research and its translation into policy and practice; proposes scientific activities for developing Disaster Risk Reduction science, and makes suggestions for how to take these forward into the 2015-2030 period. This article is published as part of a thematic collection dedicated to scientific advice to governments.
\end{abstract}

\footnotetext{
${ }^{1}$ Public Health England, London, UK ${ }^{2}$ Vice-Chair of UNISDR Scientific and Technical Advisory Group, Geneva, Switzerland Correspondence: (email: amina. aitsi-selmi@phe.gov.uk)
} 


\section{Introduction: the post-2015 agenda}

ld and new risks to communities' survival and wellbeing coexist in many countries. Rapid demographic changes, rapid and unplanned economic processes such as urbanization in hazardous areas, poor governance and the scarcity of livelihood options particularly for the poor are believed to lead to increased exposure and vulnerability, and persisting disaster losses despite better knowledge of risk (IPCC, 2014). Disasters, many of which are exacerbated or triggered by climate change and are increasing in frequency and intensity, significantly impede progress towards sustainable development (UN, 2015).

Globalization has given trade, migration, investment, climate change, security and technology an increasingly important role in shaping risk, including in low- and middle-income countries (OECD, 2008). The increasing economic interconnectedness between countries, including linked production and consumption systems worldwide, means that disasters in one part of the world can have an impact on distant locations. For example, the terrible floods of 2011 in Thailand affected the Japanese car industry and nearly brought global computer supply chains to a standstill (Chongvilaivan, 2012). Disaster impacts on such a scale call for cooperation and coordination that transcend geographical and institutional boundaries.

Four distinct and largely independent research and policy communities-disaster risk reduction, climate change adaptation, environmental management and development-have been working to reduce vulnerability to old and new risks that impact lives, livelihoods and health but face challenges in terms of facilitating learning and information exchange, as well as addressing the science-policy gaps and misaligned financial structures (Thomalla et al., 2006). However, opportunities are emerging to examine some of these challenges and barriers and build coherence across these policy streams.

For example, 2015 was an historic year for global development policy with the publication of three landmark UN agreements:

1. The Sendai Framework for Disaster Risk Reduction 20152030, which aims to reduce disaster losses in lives, livelihoods and health (agreed in March in Sendai, Japan by 187 countries);

2. The Sustainable Development Goals (SDGs) which are the successors of the Millennium Development Goals (agreed in September in Paris, France by 193 countries); and

3. The climate change agreements (December).

The coincidence of three such agreements represents a window of opportunity for scientists, policymakers and practitioners in their respective communities of interest to examine the nature of emerging risks, joint policy options and how scientific evidence and technological tools can contribute to creating effective solutions to complex problems (Aitsi-Selmi et al., 2015a). Synergies between Disaster Risk Reduction (DRR), climate change concerns and the sustainable development agenda could be articulated and leveraged more effectively for decision making and funding allocation. For example, the integration of climate change adaptation into planning and policy design can support both resilient economic development and emergency planning to save lives. It has been suggested that framing these three processes as a collective means to addressing loss and damage, is one way of capitalizing on synergies between the processes (Roberts et al., 2015).

Implementation plans underpinned by scientific evidence have the potential to target investment more accurately, contribute to greater resilience over the coming decades and save lives (Calkins, 2015). Over the implementation period of these three agreements
(2015-2030), the real impact would be in improving people's health and preserving their environment. Below we discuss the gains and opportunities for DRR science and propose ways for the scientific community to move forward on the Sendai Framework agenda.

\section{The Sendai framework for disaster risk reduction}

The Sendai Framework for Disaster Risk Reduction 2015-2030 (UN, 2015) is a voluntary agreement adopted on 18 March 2015 by $187 \mathrm{UN}$ member states after extensive negotiations at the World Conference on Disaster Risk Reduction (IISD, 2015). It has a greater emphasis on health than its predecessor-the Hyogo Framework for Action 2005 (HFA). It is also much broader in scope than the first global agreement made in the International Decade for Natural Disaster Reduction (the Yokohama Strategy and Plan of Action for a Safer World: guidelines for natural disaster prevention, preparedness and mitigation) and gives a clearer mandate emphasizing the need for more integrated disaster risk reduction that incorporates bottomup as well as top-down approaches, local scientific and technical knowledge. Finally, it draws attention to synergies with other critical policy areas including health, climate change and sustainable development (Aitsi-Selmi et al., 2015a).

This comprehensive new framework for disaster risk reduction has a single outcome, one goal, seven global targets, and four priorities for action. The Sendai Framework's outcome for the next 15 years is to achieve: The substantial reduction of disaster risk and losses in lives, livelihoods and health and in the economic, physical, social, cultural and environmental assets of persons, businesses, communities and countries. It captures the developments in science and policy thinking of the last 10-20 years in using multisectoral and multidisciplinary approaches and moving beyond a single hazard and response-focused approach to disasters, to an all-hazard, preventive approach that links with economic development and climate change (Gaillard and Mercer, 2012). Its first priority is understanding risk in all its dimensions including vulnerability and exposure.

The significance of scientific knowledge to understand risk in the Sendai Framework reflects the emphasis throughout the negotiation process of the Sendai Framework on the need to integrate science and technology to inform decision-making, as heard in statements from Member States, Intergovernmental Organizations and thematic Major Groups. Indeed, the Sendai Framework is one of the UN policy frameworks with the strongest endorsement of science.

Health-in its broadest sense ${ }^{1}$-is another area of relative prominence in the Sendai Framework. It is a notable synergy across the policy frameworks for climate change, sustainable development and DRR and could be useful in framing complex policy issues. Health puts a human face on what can sometimes seem to be a distant threat, achieve greater public resonance, and accelerate political action in ways that attention to other concepts might not. For example, it has been argued that when climate change is framed as a health issue, rather than purely as an environmental, economic, or technological challenge, it becomes clear that we are facing a predicament that strikes at the heart of humanity (Wang and Horton, 2015).

\section{Challenges and opportunities in translating evidence for disaster risk reduction}

Fifteen years ago, hazard researchers explicitly stated that improved knowledge was not sufficient by itself to reverse the upward trend in disaster losses, and called into question whether knowledge was used effectively (White et al., 2001). Despite an immense expansion of DRR related information and knowledge 
systems including publication platforms and institutional networks, the translation of this information into effective applications and decisions has been limited (Weichselgartner and Pigeon, 2015).

The need to develop the connection between science and policy and practice is considered by some to be among a priority in implementing the Sendai Framework (Pearson and Pelling, 2015). As in many areas of policy, the relationship between science and policy/practice is hampered by a number of factors including differences in language, timelines, incentive structures and values. However, steps can be taken to strengthen the interface between scientific knowledge and pragmatic decision-making as outlined below (UNISDR, 2015g):

Improving communication between scientists and decision makers. Scientists tend to communicate ideas using complex vocabulary or technical knowledge (Trainor and Subbio, 2014). Conversely, decision makers often have constraints on the amount of time they can spend in developing their technical understanding. Government and other decision-making bodies could address this through novel approaches to engage decision makers and the technical officers that support them. Alternatives to workshops including experiential learning for example through "policy games" for strategic management that have been used in Europe and the United States to improve decision quality for solving threatening strategic problems (Duke and Geurts, 2004; CDKN, 2012).

Conversely, the research community could enhance its dissemination approaches to non-technical communities through electronic media, multi-stakeholder platforms and champions of evidence-informed policy. Developing focal points of scientific advice through more widespread appointments of Government Chief Scientific Advisors at national level is one approach. The position of Chief Scientific Advisor (CSA) or its equivalent is a critical element of the scientific advisory system in a limited number of countries but networks of CSAs are starting to develop around the world. A first global meeting of CSAs and other senior scientific advisers was held in New Zealand in August 2014 (OECD, 2015). Independent international bodies of scientists such as the National Academies of Science, Engineering \& Medicine are helping to bridge disciplinary divides and synthesize knowledge to provide comprehensive risk assessments including how chemicals (endocrine disruptors) impact health and how infectious disease epidemics can destabilize economies (http:// www.nationalacademies.org/). Similarly, the InterAcademy Partnership works to strengthen the Academy function around the world including establishing science academies where they do not exist, and ensure better engagement of decision makers and wider society with science (http://www.interacademies.net/About.aspx) (The interAcademy Partnership, 2016).

Reforming incentive systems. Aligning scientific research with real problems faced by decision makers will be crucial to addressing the complex problems of the twenty-first Century (Carabine, 2015). Yet, traditional systems for incentivising and evaluating academics (such as the number of peer-reviewed journal article) are not designed to reach audiences that are nontechnical or outside the relevant scientific discipline. This can, therefore, discourage the integration of research across disciplines and minimize engagement with decision maker priorities. While some efforts have been made by providing funding to support projects that bring science to non-technical audiences (Wellcome Trust, 2016), long-term efforts are needed to align incentive and reward systems with the objective of improved science dissemination and uptake into decision-making and ensuring the research community meets the real needs of societies. For example, research funders might require applicants for research grants to systematically provide evidence that their research is in demand from decision makers (Jones, 2012).

The UK National Institute of Health and Care Excellence (https://www.nice.org.uk/) is a source of high level guidance on the best practices in clinical and social care, as well as health technologies. Its methodology ensures that research evidence, expert input and user views are combined and the recommendations are based on a measure of cost-effectiveness (Quality Adjusted Life Years) with a clear cut off. This institution provides incentives for engagement at the science-policy interface through its high level status as a government endorsed but independent organisation.

Promoting multidisciplinary and multisectoral approaches. The recognition that wicked problems-which cannot be clearly formulated and resist resolution-in policy, planning and management exist, creates an opportunity to enhance governance by promoting collaboration and coordination among scientific disciplines and policy sectors to reach mutually beneficial solutions (Head and Alford, 2015). Multisectoral platforms have been used to addressing planning issues around climate change, food security and biodiversity conservation and other complex areas of policy formulation and implementation-many of which have nested processes from the international to the local level. The improved participation, transparency and accountability they enable is considered to be best practice in governance (FAO, 2014). Similarly, the use of science from all relevant disciplines including the natural, environmental, social, economic, population health and engineering sciences will enable the delivery of an all-hazards approach and holistic risk information (Ehrler, 2015).

\section{Achievements in science translation in DRR}

A number of intergovernmental and supporting technical reports have been published in the past decade reflecting how the scientific and policy interface can work. These include the Special Report on Managing the Risks of Extreme Events and Disasters to Advance Climate Change Adaptation (SREX; IPCC, 2012) which ranks the latest scientific evidence by strength and includes a summary for policymakers. The Annual Reports of the Secretary General (ARSG) on the implementation of the International Strategy for Disaster Reduction written for the UN General Assembly (UN/GA) capture changes in policy and scientific thinking in the 2005 to 2014 period. Greater emphasis is placed on health-related issues reflecting the growing concerns expressed by many stakeholders about the devastating effects of disasters on human health (Aitsi-Selmi et al., 2015a). THE UNISDR Scientific and Technical Advisory Group (STAG) reports published in 2013 and 2015 showcase a number of case studies illustrating how can science can be translated and applied to DRR policy and practice (UNISDR, 2015a). They reinforce messages in the main reports calling for better knowledge synthesis dissemination and capacity building to ensure science is useful, usable and used (Southgate et al., 2013; Aitsi-Selmi et al., 2015b).

Case study collections focusing specifically on natural disaster risk assessment and the role of advanced modelling and capacity building in transferring science into DRR have become available (Global Facility for Disaster Reduction and Recovery (GFDRR), 2014). While successes are evident, it is recognized that new methodologies are not always widely applied in practice or taken up by users including communities at risk. Hazard maps, for example, are often used only for establishing buffer zones when they could also aid in planning of construction and development and in determining evacuation routes. More work is needed to 
develop more people-centred early warning systems that integrate vulnerability information, monitoring and evaluation (GFDRR, 2014). The people-centred approach to early-warning systems emphasizes the importance of producing warning messages that are understood by the users including local populations and ensuring that the warnings are seen as legitimate (UNISDR, 2005).

Six core scientific activities to help align research and decisionmaking were put forward by the Major Group for Science and Technology for the Sendai Framework (Aitsi-Selmi et al., 2015a). These activities are built into the Science and Technology Road Map that is being developed the S\&T community and coordinated by the UNISDR (UNISDR, 2015c). These activities are:

"Assessment of the current state of data, scientific knowledge and technical knowledge on disaster risks and resilience (what is known, what is needed, what are the uncertainties, etc.);

Synthesis of scientific evidence in a timely, accessible and policyrelevant manner;

Scientific advice to decision-makers through close collaboration and dialogue;

Monitoring and review of new scientific information and progress towards disaster risk reduction and resilience building;

Communication and engagement among policy-makers, stakeholders in all sectors and in the science and technology domains themselves to ensure useful knowledge is identified and needs are met, and scientists are better equipped to provide evidence and advice;

Capacity development to ensure that all countries can produce, have access to and effectively use scientific information" (AitsiSelmi et al., 2015a).

While the breadth of achievements in DRR science across all relevant disciplines is difficult to assess, the S\&T Road Map puts forward expected outcomes, activities and monitoring tools to set a general direction for a DRR research agenda that will support the implementation of the Sendai Framework.

Achievements over the Hyogo framework implementation period. The Hyogo Framework implementation period saw a number of new initiatives and successes of established initiatives in translating science for policy and practice. Two important improvements in DRR knowledge management are:

Better DRR information systems. The widespread need for hazard monitoring and early warning systems and the data to inform their outputs, has led to the development of a number of programs and systems to provide information and warnings. Some have been facilitated by advances in remote sensing technology, while others are leveraging advances in computer technology. Data synthesis and presentation tools such as climate forecasting and sophisticated Earth observation tools have also been developed (GFDRR, 2014; UNISDR, 2015d).

There are significant differences between countries and regions in their capacity for developing and implementing early warning systems and hazard monitoring, with Least Developed Countries (LDC) and Small Island Developing States (SIDS) being particularly limited in their ability to issue critical warnings. Most LDCs and SIDS have only a basic early warning system and a few have no such system at all (UNISDR, 2015d). Examples of global systems that attempt to address this variation by enabling the sharing of early warning and hazard monitoring information and may support LDC and SIDS include:

- The World Meteorological Organization Information System. This is a coordinated infrastructure of a global scale that enables the management of the free exchange of weather, climate and water information around the globe. It is linked to The Global Framework for Climate Services-a joint program of the World Meteorological Organisation and the World Health Organisation (https://www.wmo.int/pages/prog/www/ WIS/overview_en.html).

- The EU Humanitarian Aid and Civil Protection issues daily meteorological news flashes relevant to all regions of the world and cover non-natural hazards such as outbreaks (including the Zika virus outbreak-http://ec.europa.eu/echo/flash-latest_en)

Improvements in hazard monitoring and early warning systems have saved many thousands of lives and together are a global success story, indicating what can be achieved when science and policy are integrated effectively (Pearson and Pelling, 2015). However, increases in exposure without decreasing vulnerability may have driven rising disaster losses despite these advances (IPCC, 2014) and a deeper, multidisciplinary understanding of these dimensions of risk is needed.

Better processes for DRR knowledge translation and use. Evidence synthesis and dissemination are critical scientific functions that require investment and capacity development. At the global level, an example of successful intergovernmental evidence-translation is the Intergovernmental Panel on Climate Change (IPCC, 2014). It is multisectoral and multidisciplinary by bringing together different communities of policy and practice and addresses policy makers as its target audience.

DRR initiatives that aim to mainstream DRR and climate change adaptation across countries as part of their economic development strategies have been set up such as the GFDRR. High-income countries are also working to integrate elements of anticipation in their risk management systems. The United Kingdom was the first country to volunteer for an external peer review for "Building resilience to disasters: Assessing the implementation of the Hyogo Framework for Action (20052015)" and this was published in 2013 (UNISDR, EC, OECD, 2013). Of note, the report stated that in many respects, the UK resilience approach shows state-of-the-art innovations, including the significant use of science to support policy. The report documented, for example, the work of the Natural Hazard Partnership, which is a collaborative partnership between 12 technical and scientific agencies to work together effectively to provide emergency planners with information, research and analysis on natural hazards. Since then, other peer reviews have been undertaken and the one from Finland has also been published (UNISDR, EC, OECD, 2014). Of significance, the concept of peer-review has been included in the Sendai Framework as a valuable tool.

The UK's emphasis on futures research through the method of horizon scanning is another example of an innovative, integrated approach to knowledge use in decision-making. It aims to anticipate and prepare for new risks and opportunities through the systematic study of new developments in science and society. The Foresight report on Reducing Risks of Future Disasters aimed to demonstrate this approach by using scientific evidence and expert knowledge to anticipate future risks, identify risk drivers and therefore take action to reduce risk. Its assessments spanned the risk of earthquakes in megacities and new infectious diseases emerging in densely populated urban areas (Foresight, 2012).

Investing in institutions and groups to develop (and update) practice guidelines, standards, protocols and tools that integrate the best available evidence can help to raise standards of practice and reduce risk at all stages of the disaster cycle. This is 
particularly important at the local level where capacity for science uptake can be limited.

For UN processes, The Scientific and Technological Community Major Group was identified in Agenda 21 at the Rio Earth Summit in 1992 as one of 9 "Major Groups" (stakeholder groups) It is used by the UN to organise the inclusion of science stakeholders in UN policy processes such as the Sendai Framework. The group brings together scientists from all over the world and is co-organized by the International Council for Science (ICSU), the International Social Science Council and the World Federation of Engineering Organizations.

\section{Next steps for DRR science: promoting an all-hazard, holistic approach to risk reduction}

The Sendai Framework for Disaster Risk Reduction highlights that: "Policies and practices for disaster risk management should be based on an understanding of disaster risk in all its dimensions of vulnerability, capacity, exposure of persons and assets, hazard characteristics and the environment" (UNISDR, 2015e). As discussed above, achieving this requires that independent research and policy communities work together and overcome challenges that separate them (Thomalla et al., 2006).

From a purely scientific perspective, it can be tempting to concentrate on hard facts and empirical data that are easily measurable and useful in producing event probability estimates. However, for scientific knowledge to be useful, it needs to take into account the social context within which these events occur, as well as give estimates of the likelihoods of a variety of impacts in different scenarios, all of which require diverse types of data including qualitative data. In other words, modern disaster risk reduction requires risk to be understood in terms of the probabilities and impacts resulting from the interaction of hazards, exposure and vulnerability. For example, technological, biological and natural hazards unfold on different timescales from weeks to decades. Thus, monitoring and warning systems must be adaptable to these needs and ensure information is available to the public in a timely manner (Cutter et al., 2008).

The range of hazards that can cause a disaster has expanded in the public, policy and scientific mind as a result of devastating events such as the Fukushima nuclear disaster of 2011 in Japan and the Ebola disaster of 2014 in West Africa. The Sendai Framework has called on the expansion of the categories of hazard that fall under the umbrella of DRR to include humanmade hazards (including technological hazards and anthropogenic climate change). Some taxonomies of threat go so far as to include geopolitical conflict and financial shock alongside natural hazards, infectious disease and climate-related events (Coburn et al., 2013).

Finally, it is increasingly recognized that the linear and technocratic approaches to the science-policy relationship are no longer suitable for the world we live in, and that scientists and policymakers together with other stakeholders including the public need to engage on a regular basis and through parallel processes to co-produce knowledge with a key role for a section of scientists in translating research. The UCL Policy Commission on Communicate Climate Science has suggested that climate scientists, for example, should fulfil five roles: pure scientist, science communicator, science arbiter, issue advocate and honest broker of policy alternatives (Rapley et al., 2014). Furthermore, it has proposed that, while scientists have an essential role in shaping the dialogue around climate change with the public and decision makers, scientists should recognize the limitations of a narrow scientific perspective through active critical self-reflection and humility when interacting with others. The commission recommends that this should become the cultural norm on the part of all participants in the climate discourse (Rapley et al., 2014).

On the basis of this stock taking, we provide examples of what could be done under four areas of scientific activity (adapted from the six outlined above) that could support the synergistic implementation of the Sendai Framework.

Improving data standards. The Sendai Framework recommends improving methods for loss reporting including the integration of data and information on the multiple dimensions of risk and its underlying drivers as well as standardization of data collection and management methodologies. It calls on the DRR community: "[T]o systematically evaluate, record, share and publicly account for disaster losses and understand the economic, social, health, education, environmental and cultural heritage impacts". A clear challenge exists in achieving measurability and consistency across countries and regions while maintaining local relevance and granularity.

Reflecting this challenge, the United Nations SecretaryGeneral's Independent Expert Advisory Group on a Data Revolution for Sustainable Development has issued a worldwide call to action to improve data for sustainable development, recognizing that "data are the lifeblood of decision-making and the raw material for accountability" and inform all decisions from calculating the impacts of greenhouse gas emissions to how to spend public money. The recommendations in the call are: (1) Develop a global consensus on principles and standards; (2) Share technology and innovations for the common good; (3) Leadership for coordination and mobilization; (4) New resources for capacity development; (5) Exploit some quick wins on SDG data (Data Revolution Group, 2014).

Some of these recommendations are already being met. For example, immediately after the 3rd World Conference on Disaster Risk Reduction at which the Sendai Framework was adopted, the UN Development Programme (UNDP) and the International Research Institute of Disaster Science at Tohoku University launched the Global Centre for Disaster Statistics. The centre aims to support the integration of DRR information into development planning by generating user-friendly data that can be used for monitoring and reporting on DRR activities (UNDP, 2015).

Other, more established initiatives attempting to standardize disaster loss data include: (1) DESINVENTAR and its expansion to the many countries that still require capacity building; (2) EMDAT, which is a global database that includes both natural and technological disasters and provides essential data on the occurrence and effects of more than 17,000 disasters in the world since 1900; (3) the DATA Working Group of the Integrated Research on Disaster Risk (IRDR-DATA) which has produced a glossary of hazards worldwide; and (4) the Global Assessment Report to cite a few (IRDR, 2013; UN, 2016).

Developing holistic risk models. Risk assessment is defined by the UNISDR as "A methodology to determine the nature and extent of risk by analysing the potential hazards and evaluating existing conditions of vulnerability that together could potentially harm exposed people, property, services, livelihood and the environment on which they depend" (UNISDR, 2009). The Sendai Framework echoes this definition by promoting an approach to risk models and early warning systems that is integrated across sectors and disciplines, multidimensional by incorporating all elements of social and physical vulnerability, and focuses on the impacts of hazards rather than their mathematical probability alone. 
As discussed above, disaster risk is increasingly complex and multi-faceted with interdependencies that may be overlooked and cause cascading effects over time and space (Kumasaki et al., 2016). However, methodologies for modelling risk face a number of challenges mostly related to: the difficulty in integrating data on different hazards; a focus on probabilities of occurrence of a hazard rather than its impact; and a lack of engagement of stakeholders. Risk assessment requires considerable expertise, time, and resources at any scale (from local to global) (Birkmann, 2006).

Furthermore, risk assessment models rely on appropriate data which are not always available, as discussed above. For example, hazard datasets used in local risk models may lack the spatial detail required to capture exposure and vulnerability are not collected with the consistency and granularity required for accurate reporting and sources are often non-validated (Huggel et al., 2015; Cutter et al., 2008). Measuring vulnerability-a critical dimension of risk-requires an understanding of its underlying drivers and how these factors combine to affect resilience. While social vulnerability can be difficult to measure, useful approaches exist in understanding its relationship to socioeconomic inequality in other disciplines such the social and health sciences and (see the Social Determinants of Health approach (WHO CSDH, 2008).

In 2004, ICSU conducted a Foresight Analysis which concluded that the concept of hazard in DRR needed to be expanded to include both natural and human-induced hazards and noted that despite the variety of existing or planned activities on natural hazards, a DRR research programme that was integrated across the hazards, disciplines (natural, socioeconomic, health and engineering sciences) and geographical regions and crucially sustained over a decade was an imperative. This led to the creation of the Integrated Research on Disaster Risk (IRDR)-addressing the challenge of natural and humaninduced environmental hazards (ICSU, 2008). The programme focused mainly on natural hazards (earthquakes; volcanoes; aspects of climate change, storms (hurricanes, typhoons and so on); heat waves and droughts, however, the effects of human activities on creating or enhancing hazards, including land-use practices, would be included.

In parallel to improvements in risk assessment, the development of early warning systems is beginning to shift from a focus on the probability of a single, natural hazard to multiple (natural and man-made) hazards and their potential impacts. Advances in computer simulation and modelling have made it possible to include information on the underlying hazards, as well as on the exposure and vulnerability of populations so that warning information can truly inform response. But as yet few common standards or systems for modelling exist and this remains a challenge (UNISDR, 2015b; UNISDR, 2015f).

Improving risk information sharing. Once risk assessments are available, their uptake and use requires effective communication and dissemination to leverage any novel findings and ensure that risk information is useful, usable and used (van Aalst et al., 2008). Achieving this requires the fostering of networks across the science-policy-practice landscape through dedicated initiatives, a number of which have been mentioned above. An example at national level is the Natural Hazards Partnership Daily Hazard which provides its network members with a snapshot of the potential natural hazards and health implications that could affect the United Kingdom over the next 24 hours, 5 and 30 days. The inclusion of all hazards has clear benefits in increasing the UK's ability to respond across a range of hazards (MET Office, 2016).
The terrible 2004 Indian Ocean tsunami, which resulted in over 220,000 deaths, helped to galvanize significant momentum to apply DRR science in low- and middle-income countries, for example, in the development of a tsunami warning and mitigation systems in the Indian Ocean (UNISDR, 2015g). Indian Ocean countries developed a number of warning systems coordinated through the UNESCO Intergovernmental Oceanographic Commission. This system of warning centres uses the most advanced detection, analysis and communication technology, and has issued warnings for a number of potentially damaging events. However, issuing information did not necessarily translate into action at the community level. Further work was required to enable communities to respond effectively through the people-centred approach to early warning systems.

Building capacity across all stakeholders. Ensuring that all those working in DRR are risk-literate, as well as risk-aware is essential to achieving the aims of DRR and should be seen as an important scientific function that can be carried out by scientists themselves or specialised agencies. Where conditions allow, investing in dedicated institutions and groups to develop (and update) practice guidelines, standards, protocols and tools that integrate the best available evidence can help to promote and disseminate good practice at all levels. Formal and informal means of mass education including electronic courses, social media, experiential learning and public figures can contribute to achieving the cultural shifts necessary among professionals and the public alike for facing new and existing threats.

An area where more work is called for is in the integration of scientific advice in emergency and humanitarian response (Blanchet and Roberts, 2013) and attempts are being made to address this. The UK Scientific Advisory Group for Emergencies (SAGE-https://www.gov.uk/government/groups/scientific-advi sory-group-for-emergencies-sage) and EvidenceAid (http://www .evidenceaid.org/) are examples of new initiatives that provide timely scientific and technical advice to support decision making during emergencies for government and the wider humanitarian community respectively.

At the global level, momentum has developed for Chief Scientific Advisors to act as focal points of science-policy translation. The 23rd APEC Economic Leaders' DeclarationBuilding Inclusive Economies, Building a Better World: A Vision for an Asia-Pacific Community-made a clear statement in their declarations of their 2015 meeting: "We request the Chief Science Advisors and Equivalents to explore further the provision of coordinated scientific advice surrounding and during emergencies, in coordination with other relevant APEC for a (Para 4d; APEC, 2015a)". This was cemented in a Ministerial statement at the same meeting as follows: "We note the importance of science in disaster risk reduction and welcome the recent discussion of the Chief Science Advisors and Equivalents (CSAE) Meeting on how the provision of science advice before, during and after emergencies can contribute to risk reduction and effective disaster response" (Para 102; APEC, 2015b). The International Network for Government Science Advice (INGSA) is a model for capacity building at all levels of government by bringing scientists, academies and policymakers together and share lessons for good practice (INGSA, 2016).

\section{How do we take the evidence forward?}

Assessing progress on the science agenda for DRR requires measurement. The HFA 2005-2015 enabled the collection of DRRspecific data through self-assessment. To meet the HFA objectives, UNISDR developed an online tool (HFA Self-Assessment Tool www.preventionweb.net/english/hyogo/hfa-monitoring) to assist 
governments to assess their progress in building resilience to disaster. While these data are qualitative and subjective in nature, they have contributed to understanding governments' capabilities. Another example of good practice involving 17 countries, is the Inter-American Development Bank (http://www.iadb.org) "Indicators of Disaster Risk and Risk Management". These allow countries self-assessment of disaster risk, defining the potential economic losses in any natural disaster. At national level, up to 100 countries have established disaster loss databases for one or more hazard types. Although not all databases use the same data standard, many lessons have been learned in the design and running of these databases that can inspire a global standard for loss data.

The role of the UNISDR scientific and technical advisory group and its partners. The Sendai Framework gives a clear mandate emphasizing the need for DRR processes to be integrated across sectors and levels and incorporate bottom-up and top-down approaches, as well as local scientific and technical knowledge. Working in partnership with the UNISDR STAG and linking health to DRR to implement the Sendai Framework could have significant impact particularly when it has the following mandate in Priority 1 Para 25(g):

"Enhance the scientific and technical work on disaster risk reduction and its mobilization through the coordination of existing networks and scientific research institutions at all levels and all regions with the support of the UNISDR Scientific and Technical Advisory Group to:

- strengthen the evidence-base in support of the implementation of this framework;

- promote scientific research of disaster risk patterns, causes and effects;

- disseminate risk information with the best use of geospatial information technology;

- provide guidance on methodologies and standards for risk assessments, disaster risk modelling and the use of data;

- identify research and technology gaps and set recommendations for research priority areas in disaster risk reduction;

- promote and support the availability and application of science and technology to decision-making;

- contribute to the update of the 2009 UNISDR Terminology on Disaster Risk Reduction;

- use post-disaster reviews as opportunities to enhance learning and public policy; and

- disseminate studies"

The UNISDR Science and Technology Conference on the implementation of the Sendai Framework for Disaster Risk Reduction 2015-2030, which took place in January 27-29 2016 in Geneva (http://www.unisdr.org/partners/academia-research/con ference/2016/) aimed to promote and support the availability and application of science and technology to decision-making in DRR. The conference discussed and endorsed the UNISDR Science and Technology (S\&T) Road Map (UNISDR, 2015c) and launched the UNISDR Science and Technology Partnership for the implementation of the Sendai Framework. The S\&T roadmap defines the expected outcomes of the S\&T work under each of the four Sendai Framework priority areas of actions and proposes ways to monitor progress and needs.

\section{Conclusion}

The year 2015 has presented an opportunity for the diverse science communities to continue building on the synergies that have been identified between climate change, development and
DRR agenda. The next 15 years will be critical if collective action is to be taken to avert the impacts of new and existing disaster risk linked to unmanaged economic activity and development including through reducing unnecessary exposure and vulnerability. While there are many calls to strengthen the relationship between scientific knowledge generation and political decisionmaking, the scientific community can play its part by adapting its approach to meet the needs of an increasingly complex environmental and social landscape including through some of the proposals put forward in this chapter. It is expected that the UNISDR's leadership and its Road Map for science will support the breadth of the scientific community in delivering on the aspirations of the Sendai Framework.

\section{Note}

1 The World Health Organisation defines health broadly as "a complete state of physical, mental and social well-being, and not merely the absence of disease or infirmity" (http://www.who.int/about/definition/en/print.html).

\section{References}

Aitsi-Selmi A et al (2015a) UNISDR Science and Technical Advisory Group report 2015: Science is used for disaster risk reduction, http://preventionweb.net/go/ 42848, accessed 2 February 2016.

Aitsi-Selmi A, Egawa S, Sasaki H, Wannous C and Murray V (2015b) The Sendai framework for disaster risk reduction: Renewing the global commitment to people's resilience, health, and well-being. International Journal of Disaster Risk Science; 6 (2): 164-176.

APEC. (2015a) 2015 Leaders' Declaration-Asia-Pacific Economic Cooperation, http://www.apec.org/Meeting-Papers/Leaders-Declarations/2015/2015_aelm. aspx accessed 20 January 2016.

APEC. (2015b) 2015 APEC Ministerial Meeting-Asia-Pacific Economic Cooperation, http://www.apec.org/Meeting-Papers/Ministerial-Statements/Annual/2015/2015_ amm.aspx accessed 20 January 2016.

Blanchet K and Roberts B (2013) An Evidence Review of Research on Health Interventions in Humanitarian Crises. London School of Hygiene \& Tropical Medicine: London.

Birkmann J (2006) Measuring Vulnerability to Natural Hazards: Towards Disaster Resilient Societies. United Nations Publications: New York

Calkins J (2015) Moving Forward After Sendai: How Countries Want to Use Science, Evidence and Technology for Disaster Risk Reduction, http://currents .plos.org/disasters/article/moving-forward-after-sendai-how-countries-want-touse-science-evidence-and-technology-for-disaster-risk-reduction/, accessed 2 February 2016.

Carabine E (2015) Revitalizing evidence-based policy for the Sendai framework for disaster risk reduction 2015-2030: Lessons from existing international science partnerships. PLOS Currents Disasters. doi: 10.1371/currents.dis.aaab45b2b4106307ae2168a485e03b8a.

Chongvilaivan A (2012) Thailand's 2011 flooding: Its impact on direct exports and global supply chains. ARTNeT Working Paper Series, No. 13, http://www. unescap.org/sites/default/files/AWP\%20No.\%20113.pdf, accessed 2 February 2016.

Climate \& Development Knowledge Network. (2012) Promoting Extreme Event Learning Through Serious Fun, http://cdkn.org/2012/05/promoting-extremeeventlearning-through-serious-fun/, accessed 20 January 2016.

Coburn A, Ralph D, Tuveson M, Ruffle S and Bowman G (2013) Taxonomy of Macro-Threats: A Framework for Categorising Socio-Economic Threats and Collecting Structured Data. Centre for Risk, Judge Business School, http://www .risk.jbs.cam.ac.uk/news/events/other/downloads/130910_global_landscape/tax onomy.pdf, accessed 2 February 2016

Cutter S L et al (2008) A place-based model for understanding community resilience to natural disasters. Global Environmental Change; 18 (4): 598-606.

Data Revolution Group. (2014) A World that Counts. Mobilising the Data Revolution for Sustainable Development, http://www.undatarevolution.org/ wp-content/uploads/2014/11/A-World-That-Counts.pdf, accessed 22 January 2016.

Duke R D and Geurts J (2004) Policy Games for Strategic Management. Rozenberg Publishers: Amsterdam, Netherlands.

Ehrler J T (2015) Interdisciplinary research: Bold alliances aid translational work Nature; 517 (7535): 438-438.

Foresight Reducing Risks of Future Disasters: Priorities for Decision Makers. (2012) Final Project Report. The Government Office for Science, London, https://www.gov.uk/government/uploads/system/uploads/attachment_data/file/ 286476/12-1289-reducing-risks-of-future-disasters-report.pdf, accessed 2 February 2016. 
Gaillard J C and Mercer J (2012) From knowledge to action: Bridging gaps in disaster risk reduction. Progress in Human Geography; 37 (1): 93-114.

Global Facility for Disaster Reduction and Recovery (GFDRR). (2014) Understanding Risk in an Evolving World. Emerging Best Practices in Natural Disaster Risk Assessment, https://www.gfdrr.org/sites/default/files/publication/Understanding Risk-Web_Version-rev_1.8.0.pdf, accessed 20 January 2016.

Head B W and Alford J (2015) Wicked problems: Implications for public policy and management. Administration \& Society; 47 (6): 711-739.

Huggel C, Raissig A, Rohrer M, Romero G, Diaz A and Salzmann N (2015) How useful and reliable are disaster databases in the context of climate and global change? A comparative case study analysis in Peru. Natural Hazards and Earth System Sciences; 15 (3): 475-485.

Integrated Research on Disaster Risk (IRDR). (2013) Strategic Plan 2013-2017. International Council for Science, http://www.irdrinternational.org/wp-content/ uploads/2013/04/IRDR-Strategic-Plan-2013-2017.pdf, accessed 2 February 2016.

International Council for Science (ICSU). (2008) A Science Plan for Integrated Research on Disaster Risk Addressing the Challenge of Natural and HumanInduced Environmental Hazards, http://www.icsu.org/publications/reportsand-reviews/IRDR-science-plan/irdr-science-plan.pdf, accessed 2 February 2016.

International Institute for Sustainable Development (IISD). (2015) WCDRR Adopts Sendai Framework for Disaster Risk Reduction, http://climate-l.iisd.org/ news/wcdrr-adopts-sendai-framework-for-disaster-risk-reduction/, accessed 2 February 2016.

International Network for Government Science Advice (INGSA). (2016) About INGSA, http://www.globalscienceadvice.org/about-ingsa/, accessed 3 February 2016.

International Panel on Climate Change (IPCC). (2012) Managing the Risks of Extreme Events and Disasters to Advance Climate Change Adaptation. A Special Report of Working Groups I and II of the Intergovernmental Panel on Climate Change [Field, C.B., V. Barros, T.F. Stocker, D. Qin, D.J. Dokken, K. L. Ebi, M.D. Mastrandrea, K.J. Mach, G.-K. Plattner, S.K. Allen, M. Tignor, and P.M. Midgley (eds)]. Cambridge University Press, Cambridge, UK, and New York, $582 \mathrm{pp}$.

International Panel on Climate Change (IPCC). (2014) The IPCC Fifth Assessment Report: Impacts, Adaptation, and Vulnerability (Working Group II), http:// www.climatecouncil.org.au/uploads/cd929c5cfed40f6d7c508dd6c1f930cf.pdf, accessed 12 April 2015.].

Jones L (2012) The (Not So) Easy Task of Translating Research into Policy and Practice. Research to Action, http://www.researchtoaction.org/2012/10/the-notso-easy-task-of-translating-research-into-policy-and-practice/, accessed 20 January 2016.

Kumasaki M, King M, Arai M and Yang L (2016) Anatomy of cascading natural disasters in Japan: Main modes and linkages. Natural Hazards; 80 (3), 1425-1441.

Macqueen D et al (2014) Multi-sectoral platforms for planning and implementation- How they might better serve forest and farm producers. FFF Working paper 2. FAO, Rome, Italy.

MET Office. (2016) Natural Hazards Partnership: Daily Hazard Assessment, http:// www.metoffice.gov.uk/nhp/daily-hazard-assessment, accessed 20 January 2016.

OECD. (2008) Policy Coherence for Development-Lessons Learned. OECD Policy Brief, http://www.un.org/en/ecosoc/newfunct/pdf/hls_finland-policy_ coherence(oecd).pdf, accessed 20 January 2016.

OECD. (2015) Scientific Advice for Policy Making: The Role and Responsibility of Expert Bodies and Individual Scientists, OECD Science, Technology and Industry Policy Papers, No. 21, OECD Publishing, Paris.

Pearson L and Pelling M (2015) The UN Sendai Framework for Disaster Risk Reduction 2015-2030: Negotiation process and prospects for science and practice. Journal of Extreme Events; 2 (1), 1571001.

Rapley C G et al (2014) Time for Change? Climate Science Reconsidered Report of the UCL Policy Commission on Communicating Climate Science, https:// www.ucl.ac.uk/public-policy/policy_commissions/Communication-climatescience, accessed 20 January 2016.

Roberts E, Andrei S, Hug S and Flint L (2015) Resilience synergies in the post-2015 development agenda. Nature Climate Change; 5 (12): 1024-1025.

Southgate R J et al (2013) Using Science for Disaster Risk Reduction, https://www. unisdr.org/we/inform/publications/32609, accessed 2 February 2016.

The interAcademy Partnership. (2016) IAP Conference on Science Advice and General Assembly 2016, http://www.interacademies.net/ProjectsAndActivities/ 10880/IAPConf2016.aspx, accessed 2 February 2016.

Thomalla F, Downing T, Spanger-Siegfried E, Han G and Rockström J (2006) Reducing hazard vulnerability: Towards a common approach between disaster risk reduction and climate adaptation. Disasters; 30 (1): 39-48.

Trainor J E and Subbio T (2014) Critical Issues in Disaster Science and Management: A Dialogue Between Researchers and Practitioners, http://dspace. udel.edu/handle/19716/13418, accessed 20 January 2016.

UNISDR. (2005) KOBE REPORT draft Report of Session 2.7, Thematic Cluster 2 People Centered Early Warning Systems, http://www.unisdr.org/2005/wcdr/ thematic-sessions/thematic-reports/report-session-2-7.pdf, accessed 20 January 2016.

UNISDR. (2009) Terminology for Disaster Risk Reduction, http://www .unisdr.org/we/inform/publications/11586, accessed 31 July 2015.

UNISDR. (2015a) Science for Disaster Risk Reduction: Case studies, http://www .unisdr.org/partners/academia-research/case-studies, accessed 24 November 2015.

UNISDR. (2015b) Short Concept Note: Leveraging Science. UNISDR Science and Technology Conference on the Implementation of the Sendai Framework for Disaster Risk Reduction 2015-2030, http://www.preventionweb. net/files/45270_unisdrcnws4wglleveragingscience.pdf, accessed 20 January 2016 .

UNISDR. (2015c) Science and Technology Road Map for the UNISDR Science and Technology Partnership Supporting the Implementation of Sendai Framework for DRR 2015-2030, http://www.preventionweb.net/files/45270_unisdrscien ceandtechnologyroadmap.pdf, accessed 20 January 2016.

UNISDR. (2015d) Short concept Note: Early Warning and Hazard Monitoring. UNISDR Science and Technology Conference on the Implementation of the Sendai Framework for Disaster Risk Reduction 2015-2030, at:http://www .preventionweb.net/files/45270_unisdrcnws2wglearlywarningandhazard.pdf, accessed 24 November 2015.

UNISDR. (2015e) Short Concept Note: Risk Assessment and Management UNISDR Science and Technology Conference on the Implementation of the Sendai Framework for Disaster Risk Reduction 2015-2030, http://www .preventionweb.net/files/45270_unisdrcnws2wg3riskassessmentandmang.pdf, accessed 20 January 2016

UNISDR. (2015f) Short Concept Note: Sharing Standards, Protocols and Practices for Data Collection and Reporting. UNISDR Science and Technology Conference on the Implementation of the Sendai Framework for Disaster Risk Reduction 2015-2030, http://www.preventionweb.net/files/ 45270_unisdrcnws3wg1standardsandprotocols.pdf; http://www.prevention web.net/files/45270_unisdrcnws 2 wglearlywarningandhazard.pdf, accessed 24 November 2015

UNISDR. (2015g) Launching UNISDR science and technology partnership and the science and technology road map to 2030. Short concept note: Work stream 4, working group 1, http://www.preventionweb.net/files/45270_unisdrcnws4wglle veragingscience.pdf, accessed 11 February 2016.

UNISDR, EC, OECD. (2013) United Kingdom Peer Review-Building Resilience to Disasters: Implementation of the Hyogo Framework for Action (2005-2015), http://www.unisdr.org/files/32996_32996hfaukpeerreview20131.pdf, accessed 15 June 2015

UNISDR, EC, OECD. (2014) Finland Peer Review - Building Resilience to Disasters Implementation of the Hyogo Framework for Action (2005-2015), http://www unisdr.org/files/38523_20140717finlandpeerreport.pdf, accessed 15 June 2015].

United Nations (UN). (2015) Sendai framework for disaster risk reduction 2015 2030. http://www.unisdr.org/files/43291_sendaiframeworkfordrren.pdf, accessed 10 Feb 2016.

United Nations. (2016) Dag Hammarskjöld Library: Research Guides, http:// research.un.org/en/disaster/statistics, accessed 3 February 2016.

United Nations Development Programme (UNDP). (2015) UNDP and Tohoku University Launch "Global Centre for Disaster Statistics", http://www.undp.org/ content/undp/en/home/presscenter/pressreleases/2015/03/15/undp-and-tohoku-uni versity-launch-global-centre-for-disaster-statistics-.html, accessed 2 February 2016.

van Aalst M K, Cannon T and Burton I (2008) Community level adaptation to climate change: The potential role of participatory community risk assessment. Global Environmental Change; 18 (1): 165-179.

Wang H and Horton R (2015) Tackling climate change: The greatest opportunity for global health. The Lancet; 386 (10006): 1798-1799.

Weichselgartner J and Pigeon P (2015) The role of knowledge in disaster risk reduction. International Journal of Disaster Risk Science; 6 (2): 107-116.

Wellcome Trust. (2016) Funding: Public Engagement, http://www.wellcome.ac.uk/ funding/public-engagement/, accessed 2 February 2016.

White G F, Kates R W and Burton I (2001) Knowing better and losing even more: The use of knowledge in hazard management. Global Environmental Change Part B: Environmental Hazards; 3 (3-4): 81-92.

WHO CSDH. (2008) Closing the Gap in a Generation: Health Equity Through Action on the Social Determinants of Health. Final Report of the Commission on Social Determinants of Health. Geneva, World Health Organization.

\section{Data Availability}

Data sharing not applicable to this article as no datasets were generated or analysed during the current study.

\section{Additional Information}

Competing interests: The authors declare no competing financial interests. 
Reprints and permission information is available at http://www.palgrave-journals.com/ pal/authors/rights_and_permissions.html

How to cite this article: Aitsi-Selmi A et al. (2016) Ensuring science is useful, usable and used in global DRR and sustainable development: a view through the Sendai framework lens. Palgrave Communications. 2:16016 doi: 10.1057/palcomms.2016.16. (c) (i) This work is licensed under a Creative Commons Attribution 4.0 cc) International License. The images or other third party material in this article are included in the article's Creative Commons license, unless indicated otherwise in the credit line; if the material is not included under the Creative Commons license, users will need to obtain permission from the license holder to reproduce the material. To view a copy of this license, visit http://creativecommons.org/licenses/by/4.0/ 